\title{
Smart cities in Central and Eastern Europe: viable future or unfulfilled dream?
}

\author{
Maria Kola-Bezka \\ Nicolaus Copernicus University in Torun \\ Poland \\ mkola@econ.umk.pl \\ Mariusz Czupich \\ Nicolaus Copernicus University in Torun \\ Poland \\ czupich@umk.pl \\ Aranka Ignasiak-Szulc \\ Nicolaus Copernicus University in Torun \\ Poland \\ aranka@umk.pl
}

Abstract. The objective of the paper is to analyse the state of implementing the idea of smart cities in Central and Eastern Europe (CEE) by identifying the most widely used smart solutions on its area. The authors give definitions of a smart city and indicate the variety of methods and tools for implementing the concept in practice. Then they focus on selected rankings of smart cities and examine a few successful examples of smart initiatives from CEE. As a result of the analyses, the authors state that the philosophy of a smart city is to identify and implement the most efficient ways of providing public services in cities. The authors also found that in spite of the fact that CEE cities are not European leaders in terms of the ongoing smart initiatives and rankings of smart cities, within their territories smart solutions are implemented increasingly and more effectively. The authors indicate that the main advantage of implementing intelligent solutions in CEE cities might be building their brands and thereby encouraging the influx of new residents, investors and tourists. Although these solutions are not a comprehensive set of management tools for authorities of a city, smart cities are slowly becoming reality in CEE.

Keywords: smart city, Central and Eastern Europe, rankings of smart cities, benefits and prospects of implementation of smart solutions in CEE

JEL classification: R00, R58, O18, O52. 


\section{INTRODUCTION}

In today's world cities are the main centres of economic growth; they are also the centres inhibited by an increasing proportion of population. Cities' participation in the global GDP is currently around $80 \%$ (World Economic Forum, 2014, p. 9). The urban population in 2014 accounted for $54 \%$ of the total global population, up from 34\% in 1960, and continues to grow (WHO, 2016). In 2011 there were 480 cities with populations exceeding one million as compared to just 80 in 1950. More than 3 billion people currently reside in urban centers and this figure is expected to rise to 5 billion by 2050 (Muggah, 2012, p. 1). Municipal authorities, therefore, are facing the necessity to guarantee citizens the quality of life and public service suited to their growing expectations. A tool used by municipalities that are trying to meet these challenges is the concept of a smart city. The concept is particularly popular in major cities around the world, where, due to accumulating problems related also to high population density and air pollution, implementing highly effective solutions in different areas of the city, for instance, in the field of waste or transport management, has become a necessity. Similar problems also affect cities of Central and Eastern Europe (CEE). However, smart solutions, which give a sense of a smart city, are implemented there relatively rarely.

The objective of the paper is to analyse the state of implementing the idea of smart cities in Central and Eastern Europe (CEE) by identifying the most widely used smart solutions on its area. The authors used for this purpose the method of analysis of the subject literature, rankings and reports on smart cities, and the method of case studies, giving examples of smart initiatives successfully implemented in selected cities in CEE (ie. Budapest, Tallinn, Vilnius, Riga, Sofia, Tri-City, Poznan). The paper begins with a general overview of definitions of 'smart cities' and then discusses the variety of methods and tools for implementing the concept. The next section focuses mainly on European smart cities rankings and indicates the position of CEE cities in these rankings. Next, the paper examines successful examples of smart initiatives from CEE, assesses the state of implementation of the concept of smart city in this part of Europe and gives a brief discussion of the benefits and prospects of smart cities in CEE.

\section{THE CONCEPT OF SMART CITIES - LITERATURE OVERVIEW}

The notion of a smart city has been appearing increasingly in political and academic discourse since the end of the first decade of the twenty-first century, when a city, due to the quickly increasing number of its inhabitants, progressive global warming and the instability of the global economy, has become a place to solve problems of the contemporary world (Glaeser 2011, Lehrer 2012, Katz, Bradley, 2013).

The smart city concept originated from various definitions including those of the 'intelligent city', 'information city', 'knowledge city', 'digital city' and 'ubiquitous city'. It also has something in common with such notions as 'creative city', 'green city' and 'clever city' (see Table 1). These different 'brands' of the city concept have a different scope and place different emphases. All of them are used in the context of defining modern cities or the cities of the future, although in principle, none of them captures the essence of the concept of a smart city, and only shows some differentiators, which are also an inherent feature of the city called 'smart'. Thus, the concept of the smart city itself is fuzzy and often inconsistent (Hollands, 2008).

A smart city stands out from other centres of its 'smartness'. It can be understood as the sum of different improvements in the functioning of urban infrastructure and resources of the city, as well as public services (Allwinkle, Cruickshank, 2011, Boulton, Brunn, Devriendt, 2011, Chourabi et al., 2012, Hollands, 2008, Nam, Pardo, 2011 a, b). It makes a conscious effort to capitalize on the new information and communication technologies (ICT) landscape in a strategic way, seeking to resolve various urban problems (public service unavailability or shortages, traffic, over-development, pressure on land, environmental or sanitation 
shortcomings and other forms of inequality) in order to achieve prosperity, effectiveness and competitiveness on multiple socio-economic levels (Angelidou, 2014). The ultimate goal is to revitalize some of the city's structural (environmental and social) imbalances through the efficient redirection of information. Smart cities are envisioned as creating a better, more sustainable city, in which people's quality of life is higher, their environment more liveable and their economic prospects stronger (Lee, Hancock, Hu, 2014, p. 82).

Table 1

\section{Definitions of modern cities (examples)}

\begin{tabular}{|c|c|}
\hline City type & Definitions \\
\hline Intelligent city & $\begin{array}{l}\text { A city that monitors and integrates conditions of all of its critical infrastructures, including roads, } \\
\text { bridges, tunnels, rails, subways, airports, seaports, communications, water, power, even major } \\
\text { buildings, can better organize its resources, plan its preventive maintenance activities, and moni- } \\
\text { tor security aspects while maximizing services to its citizens (Hall, 2000). } \\
\text { An instrumented, interconnected, and intelligent city. Instrumentation enables the capture and in- } \\
\text { tegration of live real world data through the use of sensors, kiosks, meters, personal devices, ap- } \\
\text { pliances, cameras, smart phones, implanted medical devices, appliances, cameras, smart phones, } \\
\text { implanted medical devices, the web and other similar data-acquisition systems, including social } \\
\text { networks as networks of human sensors. Interconnected means the integration of those data into } \\
\text { an enterprise computing platform and the communication of such information among the vari- } \\
\text { ous city services. Intelligent refers to the inclusion of complex analytics, modelling, optimiza- } \\
\text { tion, and visualization in the operational business processes to make better operational decisions } \\
\text { (Harrison et al., 2010). }\end{array}$ \\
\hline Information city & $\begin{array}{l}\text { The 'information city' collects information from localities and delivers it to the public via the } \\
\text { internet (Lee, Hancock, Hu, 2014, p. 81). }\end{array}$ \\
\hline Knowledge city & $\begin{array}{l}\text { Knowledge Cities are cities that possess an economy driven by high value-added exports created } \\
\text { through research, technology, and brainpower. In other words, these are cities in which both the } \\
\text { private and the public sectors value knowledge, nurture knowledge, spend money on supporting } \\
\text { knowledge dissemination and discovery (i.e. learning and innovation) and harness knowledge to } \\
\text { create products and services that add value and create wealth (Carrillo, 2011). }\end{array}$ \\
\hline Digital city & $\begin{array}{l}\text { Digital city is a connected community that combines broadband communications infrastructure, } \\
\text { a flexible, service-orientated computing infrastructure based on open industry standards; and in- } \\
\text { novative services to meet the needs of governments and their employees, citizens and businesses } \\
\text { (Yovanof, Hazapis, 2009). }\end{array}$ \\
\hline Ubiquitous city & $\begin{array}{l}\text { The 'ubiquitous city' has been understood as a further extension of the digital or information city } \\
\text { in making data ubiquitously available through an embedded urban infrastructure (e.g. through } \\
\text { equipment embedded in streets, bridges and buildings) (Lee, Hancock, Hu, 2014, p. 81). }\end{array}$ \\
\hline Creative city & $\begin{array}{l}\text { A city that gives inspiration, shares culture, knowledge, and life, a city that motivates its inhabit- } \\
\text { ants to create and flourish in their own lives (O'Connor, Shaw, 2014). } \\
\text { Cities which want to be innovative, to flourish and to offer wealth and employment to its in- } \\
\text { habitants, feel that they have to adapt to arenas in which knowledge and creativity can develop. } \\
\text { Culture is often added to this arena, not just as a condition to attract the creative knowledge } \\
\text { workers, but also as a major economic sector, intricately interwoven with other sectors of the } \\
\text { economy (Musterd, Ostendorf, 2004). } \\
\text { Its aim is to develop the creativity and create environment which attracts more creative people, as } \\
\text { well as businesses and capital (Florida, 2002, Florida, Tinagli, 2004, Villalba, 2008) }\end{array}$ \\
\hline Green city & $\begin{array}{l}\text { A city which seeks to eliminate the consumption of energy from non-renewable sources (http:// } \\
\text { www.earthday.org/greencities/learn/). }\end{array}$ \\
\hline Clever city & $\begin{array}{l}\text { The clever city expresses the idea of the city where modern technologies are used solely to meet } \\
\text { the needs of its inhabitants. The use of these technologies must be justified with clear benefits for } \\
\text { residents. It must be a technology whose behaviour is understandable for the average user, so that } \\
\text { the use of services using these technologies for him was easy and comfortable, and required to } \\
\text { provide only the information and data that are absolutely necessary. The clever city is a city created } \\
\text { by and for its residents (http://www.rossatkin.com/wp/?portfolio=manifesto-for-the-clever-city). }\end{array}$ \\
\hline
\end{tabular}

Source: own compilation on the basis of the literature (i.e. Ben Letaifa, 2015). 
As Shelton, Zook and Wiig pointed out, a key element of the smart city is its ability to promote economic growth (2015). They cited IBM's marketing literature: ' $\ldots$ in the $21^{\text {st }}$ century, cities compete globally to attract both citizens and business. A city's attractiveness is directly related to its ability to offer the basic services that support growth opportunities, build economic value and create competitive differentiation. Potential inhabitants, of both the commercial and residential variety, are a discriminating lot, and they are looking for cities that operate efficiently and purposefully. They are looking for smarter cities' (IBM Smarter Cities 2012 in Shelton, Zook, Wiig, 2015, p. 3).

Although when defining a smart city the central issue is ICT, it does not work only through their implementation. It does not guarantee the real smartness of cities and it actually does not necessarily make people think or act smart by themselves. Technology is only a tool for social, environmental, economic and cultural development (Nam, Pardo, 2014). A city is smart when investments in human and social capital, traditional transport and modern digital infrastructure fuel sustainable economic growth and a high quality of life, with a wise management of natural resources through participatory governance (Giffinger et al., 2007, Nijkamp, Kourtit, 2011, in: Steenbruggen, Tranos, Nijkamp, 2015, p. 337).

Smart city strategies can be implemented variously. With a spatial reference four strategic choices can be identified: national versus local strategies, strategies for new versus existing cities, hard versus soft infrastructure-oriented strategies and sector-based versus geographically-based strategies (Angelidou, 2014). In the first mentioned a major differentiating characteristic among smart city strategies is whether they concern an entire country or nation, or they are focused on a more local level (city, metropolitan area or region). In the second one the criterion is the urban development stage of the city. Thus, one can say about strategy of existing cities or new ones (greenfield cities, cities from scratch or planned cities). The third strategic choice refers to the question whether the smart city strategy will target the efficiency and technological advancement of the city's hard infrastructure systems (i.e., transport, water, waste, energy) or the soft infrastructure and the people of the city (i.e., social and human capital: knowledge, inclusion, participation, social innovation, social equity). The last one refers to whether smart city strategy aims at the transformation of specific economic sectors of the city (such as business, housing, commerce, governance, health, education etc., without placing specific emphasis on the geography of each sector) or geographically-determined districts or clusters (such as business districts, research and development clusters, university and education areas, tourism and leisure clusters).

Real applied smart city strategies lie somewhere in-between the extremes of the available strategic choices. However, they all are characterized by such features as foresight, advanced technologies, ICT infrastructure and security. The smart city is a city whose development plans include the economy, governance, mobility, environment and living conditions. It is a city functioning on the basis of resources and is active and independent in decision making and informed residents (Giffinger et al., 2007). The smart city uses advanced technologies in order to improve the efficiency of the most important elements of urban and/or social infrastructure and the efficiency of public services (Washburn et al., 2010). Skilfully implemented and deployed ICT infrastructure is conducive to improving the efficiency of public management in a smart city and increases the involvement of citizens in the life of the city (Hollands, 2008). And finally, a smart city is safe for people and the environment; it is an effective urban centre with advanced infrastructure, such as sensors, electronic devices and networks used to stimulate sustainable economic growth and improve the quality of life in the city (Caragliu, Del Bo, Nijkamp, 2011). 


\section{CEE CITIES IN GLOBAL RANKINGS OF SMART CITIES}

As the concept of smart cities has grown in popularity, various reports and rankings of 'smart' cities have started to be published. They differ in the scope and methodology of preparation. Assessments of 'the smartness' of cities are most frequently made on the basis of certain indicators selected to suit the definition of a smart city adopted by the authors of a given ranking. Sometimes comparisons are made of individual initiatives categorised as smart and carried out in different cities, using the case study method. Such analyses allow the identification of best practices as regards some selected areas of the city's functioning (e.g., transport, energy, communication). The scientific value of many rankings is sometimes questioned due to the frequently subjective selection of analysed variables and due to a significant differentiation of analysed cities in terms of their size or functions performed. These rankings, however, are highly popular in the media and are an important instrument of territorial marketing (particularly when they indicate a high position in the ranking of a given city or an improved position in relation to the previous edition). The undoubted advantage resulting from the development and dissemination of such rankings is the ability to attract the public attention and initiate discussions on urban development policies. Rankings can be a tool of competitive struggle as well as the basis for specifying a city profile. They can also be used to identify best practices, disseminate them and initiate the learning process (Giffinger and Haindl, 2009, p. 705).

CEE cities are considered rarely in global rankings of smart cities, which results primarily from the fact that those rankings take into consideration mostly largest metropolitan areas and cities of the world, and CEE cities do not belong to them. Moreover, the scale of smart solutions implemented by CEE cities is rather small. As follows from a ranking of smart cities published in February 2015 by Juniper Research, which was compiled based on analyses of each city's smart capabilities (use of smart grids, smart traffic management and lighting, social cohesion, etc.), the global leader is Barcelona, and is ahead of such metropolises as New York and London (http://www.juniperresearch.com/press/press-releases/barcelona-named-globalsmart-city-2015). CEE cities are also infrequently included in rankings of quality of life. In the Mercier Research ranking developed for 2012, where the leader was Vienna, among CEE cities Budapest took the lead (67th place) and was followed by Vilnius (74th place) and Prague (75th place) (https://eu-smartcities. $\mathrm{eu} /$ content/best-cities-environment-and-infrastructure). However, CEE cities are regularly included in reports on European smart cities. As can be inferred from these reports, CEE cities occupy remote positions, if compared with other cities of Europe.

Interesting conclusions about the level of CEE cities smartness can be drawn from the results analysis of the survey made on European medium-sized cities within a project titled European Smart Cities (ESC). The project resulted in developing a ranking of smart cities. The first editions of the ranking were limited to cities with a population between 100,000 and 500,000, and with at least one higher education institution and impacting an area inhabited by no more than 1.5 million people. So far three editions of the ranking (2007, 2013 and 2014) have been published enhancing gradually the array of instruments and improving the research methodology. Assessments of city smartness was made with the use of indicators (their number rose from 74 in 2007 and to 81 in 2014) describing the following six major areas that make up a smart city model (http://www.smart-cities.eu/model.html): smart living, smart mobility, smart governance, smart economy, smart environment, and smart people. The first edition of the ranking, which covered 70 European medium-sized smart cities, included CEE cities, however, they were not classified into the group of ranking leaders. The cities with the best positions in the ranking were two Slovenian cities - Ljubljana and Maribor (17th and 30th place respectively), then the capital of Croatia - Zagreb (35th place), Estonian Tartu (40th place), two Czech cities - Plzen and Usti upon Labem (42nd and 44th place), Nitra from Slovakia (47th place), and Rzeszów from Poland (48th place). Sixteen CEE cities were ranked between the 50th and 
70th positions, including 3 Polish ones: Białystok (53rd), Bydgoszcz (57th) and Szczecin (62nd) (Giffinger et al., 2007, p. 16). The 2014 ranking covered 77 cities, including 24 CEE cities. Ljubljana was the highest ranked one (15th place) and the next was Maribor (40th place). Other CEE cities were not included in the first forty. Six Polish cities appeared in the ranking - Rzeszów (56th place), Szczecin (57th), Bydgoszcz (62nd), Białystok (66th), Kielce (68th), and Suwałki (70th) (http://www.smart-cities.eu/?cid=3\&ver=3). In 2015 the research methodology was changed, replacing the ranking with city profiles and enhancing the population criterion in the city selection process (the survey covered cities with a population ranging from 300,000 to $1,000,000$ people). Profiles of studied cities can be compared against ranking leaders by means of the ESC project website.

Despite the fact that within the ESC project data were standardized, it was criticized for taking into account only quantitative elements such as, for instance, the number of implemented modern technologies and smart control systems. It was argued that while assessing the level of city smartness quality dimensions (for example, comprehensiveness and effectiveness in achieving the mission statement aimed at raising the standard of living and making the city offer more attractive) should also be taken into account (http://www. designforall.pl/jak-zmierzyc-inteligencje-miasta-aspirujacego-do-miana-smart-city/).

The Mapping Smart Cities in the EU report has become a popular source of information about the smartness of European cities. It was prepared in 2014 for the European Parliament's Industry, Research and Energy Committee with a view to providing basic information as well as the basis for drawing conclusions on the level of the implementation of the idea of smart cities in the context of achieving the objectives of the Europe 2020 Strategy. As follows from the report, few cities located in CEE correspond to the broad definition of a smart city. The authors analysed within the study 468 cities situated in the EU-28, with a population in excess of 100,000 . The cities were analysed by their compliance with the developed definition and by the occurrence of smart initiatives (the information taken for the analysis was obtained from the Internet, e.g., websites of realised projects). On this basis 240 cities with a noticeable activity in the analysed sphere were identified (Manville et al., 2014, pp. 15-16). The European leader was Copenhagen - a city that in 2014 won also the international World Smart Cities Award for the Copenhagen Connecting plan, and in 2015 signed an agreement with the Japanese company Hitachi to establish the world's first Big Data platform for an entire city enabling companies, the public sector and citizens to use the data volumes found in large urban environments (http://www.copcap.com/newslist/2015/denmark-tops-eu-28-smart-city-ranking). When compared to cities in other EU countries, CEE cities were less frequently qualified as smart. This was particularly evident in the case of Polish and Lithuanian cities. Cities from other CEE countries owed their relatively better situation mainly to the implementation of smart initiatives in the environmental area (Manville et al., 2014, pp. 40-43).

As follows from the analysis of selected European rankings identifying smart cities, CEE cities are not leaders in terms of the number, scale and scope of ongoing smart initiatives. However, these rankings provide useful information in the form of benchmarking to cities. They make it possible to make comparisons of a given city along with its used solutions aspiring to the status of being smart with cities-leaders and their practices recognized as the best ones in the field. It seems that the level of the usefulness of these rankings is rising, since they are increasingly built on the basis of the qualitative characteristics measuring the city smartness. They promote thus the idea of a smart city understood not only as a result of embedding innovative systems and ICT technologies in the urban space, but primarily as a joint venture carried out by residents, authorities, local entrepreneurs and other institutions that matches the needs of city users and provides the most efficient implementation of public services. 


\section{SMART INITIATIVES IN CEE - CASE STUDIES}

An example of the CEE city, which successfully implements projects related to smart city is Budapest. Many solutions aimed at improving the quality and level of utility of public space work there. Significant changes have been made mainly in transport. A special system FUTAR is used in public transport (https:// www.telekom.com/media/enterprise-solutions/293550). It is controlled by the management center, which analyzes the data in terms of the traffic, the current position of public transport vehicles and on the basis the planned timetables and control lights at junctions on major routes of the city. About 2.3 th. urban vehicles are equipped with location systems, which allow the transmission of information on actual time of arrival at the bus stops, where they are displayed on the boards with variable content.

More or less advanced systems for traffic control are used in many CEE cities. An example might be Polish Tricity, where TRISTAR system is implemented (https://www.tristar.gdynia.pl/pages/public/simple_ map.xhtml). It will cover a total of 141 crossings, of which 67 in Gdansk, 60 in Gdynia and 14 in Sopot. The main point of this system, developed by scientists from the Technical University of Gdansk, is a special computer that is connected to two traffic control centres located in the Gdansk and Gdynia. The intensity of traffic is tracked by hundreds of cameras, sensors and induction loops. As a part of the system, it is planned to install over 100 cameras and speed cameras guarding the safety of drivers and observance of traffic rules.

An innovative approach to public transport is represented by the Estonian city of Tallinn, where, in 2015 the old trolleybuses were replaced by 24 hybrid buses that meet emission Euro 6 standard (http:// www.baltic-course.com/eng/transport/?doc=103957). Besides, since 2013 the so-called green card was implemented allowing residents a free public transport. The benefits achieved include among others reduction of the traffic by $20 \%$ and number of people using public transport increase by $6 \%$ (Light House, 2015). The authorities of Tallinn also put a great emphasis on reducing the energy consumption of buildings, which the city owns. For several years, they consistently implement thermal efficiency improvements of public buildings, installing thermostats and changing heating systems powered by renewable energy. In 2011-2013, 37.5 million EUR was allocated for this purpose, while in the period 2015-2020 another such investments will cost 240 million EUR (Light House, 2015). The current result of this is the reduction of energy consumption by $3370 \mathrm{MWh}$ per year. In addition, the city became involved in the construction of several energy self-sufficient buildings, which use heat pumps and solar panels. Noteworthy is the fact that private homeowners can benefit from training in the field of energy savings, loans and the financial support offered by the city administration. This enables them to improve the isolation of the homes, and installing smart meters, which are followed by remote reading and which, through continuous monitoring, can optimize energy consumption.

Another example of activities in the area of energy policy is the investment in Poznan. The administration of the city used the formula of public-private partnership and in April 2013 signed an agreement for the construction and operation of waste incineration (PARP, 2014, pp. 35-54). This agreement amounted to the sum of 725 million PLN, and assumed that the private partner will design, build, and will be for 25 years, the operator of thermal treatment of residual fraction of mixed municipal waste plant. The private partner will perform waste collection and produce adequate volume of electricity and heat. The installation will be able to process approx. 210 th. tonnes of waste per year and produce $18 \mathrm{MW}$ of electricity and 34 MW of heat.

A common subject of improvements in the cities is lighting. Such action were undertaken, inter alia, by Budapest (http://dailynewshungary.com/budapest-tests-smart-city-application/). Lamps controlled by special modules adjust the light intensity to car traffic, cycling and walking. A network of sensors placed on lamps work on the principle of motion sensors capture an approaching vehicle or pedestrian. The data col- 
lected from the sensors is transmitted to the control center, where the work of lamps is analysed and modified. An additional function of the sensors is the ability to measure noise and air pollution. This information will be ultimately distributed by the application on the phone. In this way, residents can monitor air pollution and traffic in different parts of the city. This solution brings the city significant savings associated with a reduction in working hours of lamps. A similar system operates in Latvian Riga and Romanian Brasov. Furthermore, Lithuanian Vilnius since 2014 has been implementing the project of public-private partnership with the Italian company, which aims to replace lighting for LEDs. As a result, the city is expected to save up to $70 \%$ of energy consumption, which will result in savings of EUR 2 million per year (The New Economy, 2014).

An interesting project in the field of e-government was implemented in 2013-2014 in Bulgarian Sofia. The city authorities decided to computerize largely the work of their offices and in cooperation with the Ministry of Transport and Information and Communication Technologies introduced 50 e-services to its residents. The e-government services were offered to individuals and businesses and include among others issuing and accepting certificates, confirmations and documents from the registrar's office, on local taxes and fees, municipal enterprises, etc. (https://usl.sofia.bg/ePortal/pages/services.xhtml). Access to these services is possible after obtaining of a special card by residents that allows identifying a specific person by electronic signature and identification number. The large popularity of these solutions resulted that the Ministry of Transport and Information and Communications Technology, decided to implement them in other cities as Burgas, Gabrovo and Radomir. The project was supported by the EU under the European Social Fund.

Using the Internet as a medium of communication between the office and the residents is also popular in Lithuanian Vilnius. The city authorities have set up an e-platform, through which residents can submit their suggestions and ideas for investment, to express opinions on the topics discussed at sessions of the city council and participate in surveys on topics important to the city. Moreover, the platform allows the access to over 100 e-services (The New Economy, 2014).

One of the projects aimed at improving the quality of public services and living standards is a project carried out in Latvian Riga. The city government initiated the implementation of city card, which is an innovative form of payment. It can be used for payment for public transport, urban parks, „park and ride” places, as well as museums, concert halls, etc. (http://www.stepupsmartcities.eu/Portals/51/Documents/3\%20 point $\% 202 \% 20$ reports/Riga\%20Smart\%20cards.pdf). The main objective that led the government to promote public transport and consequently reduce $\mathrm{CO} 2$ emissions, and also giving facilitations for citizens using the public services.

Another solution aimed to make life easier in the city are the applications on the phone offering various utilities. In Budapest locals enjoy free application, which includes a map of the city with the possibility of tracing the addresses and routes and timetables for all public transport lines (http://en.smartcity.hu/). The application has offline mode, which greatly facilitates the use of it. There can be memorized the most common destinations, which will be displayed on the main map and it allows to find the nearest bus stops.

Many mobile solutions are used in Polish cities. Very popular are the phone city guides. They are used among others in Szczecin, Gdansk, Lodz, Bydgoszcz. On the other hand, in Warsaw, Cracow, Wroclaw, Tychy and other cities a free application on the phone is available informing on the dates of removal of waste from individual districts, rebounding bulky waste, waste segregation. It also contains links to environmental organizations and information about ecological events, etc.

In conclusion, many of the solutions are already very widespread in the cities of the CEE. In addition to the above the most common are connected with: renewable energy, city bike, hot spots, urban videomonitoring, participatory budgets. Smart solutions are implemented, however, mainly in large cities, often capitals. What's more, they do not form a complete system of innovative city management. Rather, they are 
selectively used tool, most often in the field of transport and energy. This is also true for Poland. Studies conducted in Polish cities with county rights showed that major cities showed a high or very high activity of actions that could be considered compatible with the concept of smart city. The problem, however, was that they were difficult to qualify as a systematic and set in order (Stawasz, Sikora-Fernandez, 2015, pp. 93-114).

It should be noted that in the analyzed CEE cities smart city concept is only a part of the ongoing development plans, and not a permanent part of the comprehensive management of the city. The subjects responsible for urban development are guided in their actions, above all, by the need to reduce energy and transportation costs. It is still too early to classify these cities among the innovative ones and treated equally to Barcelona,Copenhagen and London. Long economic and social delay of CEE countries is also reflected in terms of the functioning of cities and their financial capabilities. Still, optimism can be seen in the fact that the municipal authorities in this part of Europe are open to new trends in urban policy. This is expressed through participation in organizations associating partner cities, sharing best practices in the field, or the implementation of smart city projects through the implementation of projects in the model of public-private partnership.

\section{CONCLUSIONS}

The idea of smart city consists in creating and exploiting relationships and links between human and social capital and between ICT with a view to generating sustainable economic growth of the city and improve the quality of life of its inhabitants. In practice the idea of a smart city can be variously implemented. One can identify the following four strategic choices: national versus local strategies, strategies for new versus existing cities, hard versus soft infrastructure-oriented strategies and sector-based versus geographically-based strategies.

No doubt the implementation of smart solutions in cities around the world contributes to the improvement of their functioning and provides them with numerous benefits. These benefits can be perceived in different areas of the city and by its various stakeholders. Due to the diversity of cities and the conditions under which they operate as well as due to different strategies applied in smart city development, it is not possible to identify a universal and complete set of them. Nonetheless, based on the examples of smart initiatives and projects presented in this article, one can assume that disseminating the idea of a smart city in CEE cities brings them a lot of positive effects, for example, in the forms of improving the functioning of public administration, possibilities of shaping the offer of public services in line with the preferences of residents, lower costs of rendering public services, or reducing combustion emissions and air pollution. For CEE cities a particular advantage resulting from the implementation of the smart city concept may prove to be creating the image of a modern and functional city. As examples from around the world show, the implementation of smart solutions in various areas of the functioning of the city allows its brand to be developed, thereby encouraging the inflow of new residents, investors and tourists.

Smart city strategy can also be a tool for effective global competitive struggle for resources (human and financial capital). In developing countries, which include CEE countries, it may be therefore a way to improve the level and quality of life due to investments made in modern sectors of the economy being developed in the city which use smart infrastructure offered by the city as well as knowledge and creativity of its inhabitants. In other words, it can contribute to dynamic economic growth and creating new, sustainable jobs. Developing a city through the implementation of smart strategies can reduce the risk of 'the import of problems' faced by other cities in the region or country (e.g., outflow of young and educated people, depopulation, decline in the competitiveness of goods and services 'exported' by businesses located in the city). It can also be a way to reduce challenges such as, for instance, deepening of social, economic and environmental inequalities related to the operation of the Single European Market. 
As follows from the analysis of European rankings identifying smart cities, CEE cities in spite of being present in these rankings, in terms of numbers, scale and scope of the ongoing smart initiatives clearly lag behind other cities of the continent. Their presence in these rankings indicates, however, that within their territories smart solutions are implemented increasingly and more effectively, improving the quality of life of their residents and the functioning of other stakeholders of the city. Although these solutions do not constitute a comprehensive set of management tools for the city but rather a means to reduce its operating costs, one can state that smart cities in CEE become a viable future.

\section{REFERENCES}

Allwinkle, S., Cruickshank, P. (2011), Creating smarter cities: An overview, Journal of Urban Technology, No. 18(2), pp. $1-16$.

Angelidou, M. (2014), Smart city policies: A spatial approach, Cities, No. 41, pp. 3-11.

Ben Letaifa, S. (2015), How to strategize smart cities: Revealing the SMART model, Journal of Business Research, No. 68, pp. 1414-1419.

Boulton, A., Brunn, S.D., Devriendt, L. (2011), Cyberinfrastructures and 'Smart' World Cities: Physical, Human and Soft Infrastructures, [in:] Derudder, B., Hoyler, M., Taylor, P.J., Witlox, F. (eds.), International Handbook of Globalization and World Cities, Cheltenham, Edward Elgar.

Caragliu, A., Del Bo, Ch., Nijkamp, P. (2011), Smart Cities in Europe, Journal of Urban Technology, Vol. 18, No. 2, pp. 65-82.

Carrillo, F.J. ed. (2011), Knowledge Cities: Approaches, Experiences and Perspectives, Routledge, London, New York.

Chourabi, H., Nam, T., Walker, S., Gil-Garcia, J.R., Mellouli, S., Nahon, K., Pardo, T.A., Scholl, H.J. (2012), Understanding Smart Cities: An Integrative Framework, Proceedings of 45th Hawaii International Conference on System Sciences.

Florida, R. (2002), The Rise of the Creative Class: And How It's Transforming Work, Leisure, Community and Everyday Life, Basic Books, New York.

Florida, R., Tinagli, I. (2004), Europe in the Creative Age, Carnegie Mellon, Software Industry Centre, Demos.

Giffinger, R., Fertner, C., Kramar, H., Kalasek, R., Pichler-Milanovic, N., Meijers, E. (2007), Smart cities - Ranking of European medium-sized cities (Report), Centre of Regional Science, Vienna UT, http://www.smart-cities.eu/download/smart_cities_final_report.pdf (referred on 15/07/2015).

Giffinger, R., Haindl, G. (2009), Smart Cities Rankings: an Effective Instrument for the Positioning of the Cities?, Barcelona, http://upcommons.upc.edu/bitstream/handle/2099/11933/05_PROCEEDINGS_M5_01_0014.pdf?sequence=1 (referred on 13/11/2015).

Glaeser, E.L. (2011), Triumph of the City: How Our Greatest Invention Makes Us Richer, Smarter, Greener, Healthier, and Happier, Penguin Press, New York.

Glasmeier, A., Christopherson, S. (2015), Thinking about smart cities, Cambridge Journal of Regions, Economy and Society, No. 8, pp. 3-12.

Hall, P. (2000), Creative cities and economic development, Urban Studies, No. 37(4), pp. 633-649.

Harrison, C., Eckman, B., Hamilton, R., Hartswick, P., Kalagnanam, J., Paraszczak, J., et al. (2010), Foundations for smarter cities, Journal of Research and Development, No. 54(4), pp. 350-365.

Hollands, R.G. (2008), Will the real smart city please stand up?, City, No. 12(3), pp. 303-320.

Katz, B., Bradley, J. (2013), The Metropolitan Revolution: How Cities and Metros Are Fixing Our Broken Politics and Fragile Economy, Brooking Institution Press, Washington.

Lee, J.H., Gong Hancock, M., Hu, M-Ch. (2014), Towards an effective framework for building smart cities: Lessons from Seoul and San Francisco, Technological Forecasting \& Social Change, No. 89, pp. 80-99. 
Lehrer, J. (2012), A Physicists Solves the City, The New York Times, 17 December.

Light House (2015), Report - Specific ambitions of the R4E partner cities. Ambitions of Tallin, http:// www.tue-lighthouse. $\mathrm{nl} /$ Publications.html (referred on 18.03.2016).

Manville, C., Cochrane, G., Cave, J., Millard, J., Pederson, J.K., Thaarup, R.K., Liebe, A., Wissner, M., Massink, R., Kotterink, B. (2014), Maping Smart Cities in the EU, Study, Directorate General for Internal Policies, Policy Department A: Economic and Scientific Policy, January.

Muggah, R.(2012), Researching the Urban Dilemma: Urbanization, Poverty and Violence, International Development Research Centre, Ottawa, Canada.

Musterd, S., Ostendorf, W. (2004), Creative cultural knowledge cities: Perspectives and planning strategies, Built Environment, No. 30(3), pp. 188-193.

Nam, T., Pardo, T.A. (2011a), Conceptualizing Smart City with Dimensions of Technology, People, and Institutions, Proceedings of the $12^{\text {th }}$ Annual International Conference on Digital Government Research, June 12-15, College Park, MA, USA.

Nam, T., Pardo, T.A. (2011b), Smart City as Urban Innovation: Focusing on Management, Policy, and Context, Proceedings of the $5^{\text {th }}$ International Conference on Theory and Practice of Electronic Governance, September 26-28, Tallin, Estonia.

Nam, T., Pardo, T.A. (2014), The changing face of a city government: A case study of Philly311, Government Information Quarterly, No. 31, pp. 1-9.

Nijkamp, P., Kourtit, K. (2011), Global challenges and local responses in the urban century: A scoping document, Amsterdam, Vrije Universiteit.

O'Connor, J., Shaw, K. (2014), What next for the creative city?, City, Culture and Society, No. 5(3), pp. 165-170.

PARP (2014), Biuletyn Partnerstwa Publiczno-Prywatnego, Warszawa.

Shelton, T., Zook, M., Wigg, A. (2015), The 'actually existing smart city', Cambridge Journal of Regions, Economy and Society, No. 8, pp. 13-25.

Smart cities. Ranking of European medium-sized cities (2007), Centre of Regional Science, Vienna UT, October.

Songdo City, http://www.songdo.com/songdo-international-business-district/news/in-the-news.aspx (referred on 08/11/2015).

Stawasz D., Sikora-Fernandez D. (eds.) (2015), Zarządzanie w polskich miastach zgodnie z koncepcja smart city, Wydawnictwo Placet, Warszawa.

Steenbruggen, J., Tranos, E., Nijkamp, P. (2015), Data from mobile phone operators: A tool for smarter cities?, Telecommunications Policy, No. 39, pp. 335-346.

The New Economy (2014), Vilnius becomes one of Europe's smartest cities, 21.07, http://www.theneweconomy.com/business/vilnius-becomes-one-of-europes-smartest-cities (referred on 18.03.2016).

Washburn, D., Sindhu, U., Balaouras, S., Dines, R.A., Hayes, N.M., Nelson, L.E. (2010), Helping CIOs Understand "Smart City" Initiatives, February, http://www-935.ibm.com/services/us/cio/pdf/forrester_help_cios_smart_city. pdf (referred on 18.03.2016).

World Economic Forum (2014), The Competitiveness of Cities. A report of the Global Agenda Council on Competitiveness, August, http://www3.weforum.org/docs/GAC/2014/WEF_GAC_CompetitivenessOfCities _Report_2014.pdf (referred on 18.03.2016).

World Health Organization, Global Health Observatory Data, http://www.who.int/gho/urban_health/situation_trends/ urban_population_growth_text/en/ (referred on 18.03.2016).

Villalba, E. (2008), On Creativity. Towards an Understanding of Creativity and its Measurements, JRC Scientific and Technical Reports, European Communities, Luxembourg.

Yovanof, G.S., Hazapis, G.N. (2009), An architectural framework and enabling wireless technologies for digital cities \& intelligent urban environments, Wireless Personal Communications, No. 49(3), pp. 445-463. 


\section{INTERNET SOURCES}

Http://dailynewshungary.com/budapest-tests-smart-city-application/ (referred on 18.03.2016).

Http://en.smartcity.hu/ (referred on 18.03.2016).

Http://www.baltic-course.com/eng/transport/?doc=103957 (referred on 18.03.2016).

Http://www.copcap.com/newslist/2015/denmark-tops-eu-28-smart-city-ranking (referred on 12/11/2015).

Http://www.designforall.pl/jak-zmierzyc-inteligencje-miasta-aspirujacego-do-miana-smart-city/ (referred on 16/07/2015).

Http://www.earthday.org/greencities/learn/ (referred on 15/07/2015).

Http://www.juniperresearch.com/press/press-releases/barcelona-named-global-smart-city-2015 (referred on 12/11/2015).

Http://www.rossatkin.com/wp/?portfolio=manifesto-for-the-clever-city (referred on 15/07/2015).

Http://www.smart-cities.eu (referred on 12/11/2015).

Http://www.stepupsmartcities.eu/Portals/51/Documents/3\%20point\%202\%20reports/Riga\%20Smart\%20cards.pdf (referred on 18.03.2016).

Https://eu-smartcities.eu/content/best-cities-environment-and-infrastructure (referred on 12/11/2015).

Https://usl.sofia.bg/ePortal/pages/services.xhtml (referred on 18.03.2016).

Https:// www.telekom.com/media/enterprise-solutions/293550 (referred on 18.03.2016).

Https://www.tristar.gdynia.pl/pages/public/simple_map.xhtml (referred on 18.03.2016). 